\title{
Electrochemical and Quantum Chemical Investigations of the Insecticide Fipronil
}

\author{
Fabiano Okumura, ${ }^{*, a}$ Raquel B. Amaral, ${ }^{b}$ Ednilsom Orestes, ${ }^{c}$ Albérico B. F. Silva ${ }^{b}$ and \\ Luiz Henrique Mazo ${ }^{b}$
}

\author{
${ }^{a}$ Centro Nacional de Pesquisa Milho e Sorgo, Empresa Brasileira de Pesquisa Agropecuária, \\ Rodovia MG 424, km 65, 35701-970 Sete Lagoas-MG, Brazil \\ ${ }^{b}$ Instituto de Química de São Carlos, Universidade de São Paulo, Av. Trabalhador São-Carlense, \\ 400, CP 780, 13560-970 São Carlos-SP, Brazil
}
${ }^{c}$ Escola de Engenharia Industrial Metalúrgica, Universidade Federal Fluminense, Av. dos Trabalhadores, 420, 27255-125 Volta Redonda-RJ, Brazil

\begin{abstract}
This work describes an electrochemical and quantum chemical investigation of the fipronil insecticide. Cyclic voltammetry (CV) and square wave voltammetry (SWV) experiments were performed over a graphite-polyurethane (GPU) composite electrode. The fipronil molecule presents an one-electron irreversible oxidation reaction. Profiting the SWV signal a square wave stripping voltammetry (SWSV) procedure to determine the fipronil molecule in a $0.10 \mathrm{~mol} \mathrm{~L}^{-1}$ Britton-Robinson buffer solution, $\mathrm{pH} 8.0$ was developed with accumulation potential and time of $0.50 \mathrm{~V}$ and $120 \mathrm{~s}$, respectively. The limits of detection and quantification were 0.80 and $2.67 \mu \mathrm{g} \mathrm{L} \mathrm{L}^{-1}$, respectively. Recovery tests were performed in three natural waters samples with values ranging from 99.67 to $101.37 \%$. Quantum chemical studies showed that the nitrogen atom of the pyrazole group is the most probable oxidation site of the fipronil molecule.
\end{abstract} theory

Keywords: fipronil, graphite-polyurethane, square wave voltammetry, density-functional

\section{Introduction}

Fipronil, (5-amino-1-[2,6-dichloro-4-(trifluoromethyl)phenyl]-4-[(trifluoromethyl)-sulfinyl]- $1 \mathrm{H}$-pyrazole-3carbonitrile), is a potent insecticide of phenylpyrazole group used in agriculture to control pests with high efficiency at very low doses. ${ }^{1-3}$ Regent $^{\oplus}$, Frontline ${ }^{\circledR}$, Termidor ${ }^{\circledast}$, among others, are commercial products that contain fipronil as active ingredient. It is used against beetles, ticks, fleas, termites and other pests. ${ }^{4}$ It is currently registered in more than 70 countries for the control of insect pests in more than 100 crops such as corn, soybean, sugar cane and wheat. The chemical structure of the fipronil molecule is shown in Figure 1.

The fipronil molecule acts disrupting the insect's central nervous system by blocking the passage of gamma aminobutiric acid (GABA) regulated chloride channel causing paralysis, convulsions and death. ${ }^{5}$ In some countries it was banned because a strong undesirable effect

*e-mail: fabiano.okumura@embrapa.br

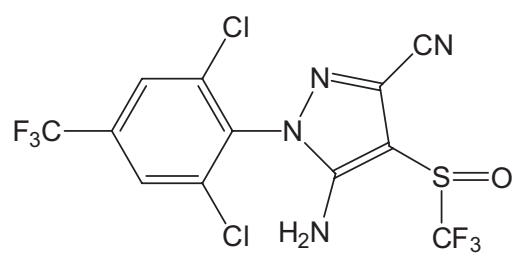

Figure 1. Chemical structure of fipronil.

against honeybees and non-target insects were seen with serious consequences like a great environmental impact and economical prejudices.

According to the literature, ${ }^{6}$ the fipronil molecule degrades to four breakdown products when exposed to different conditions: fipronil molecule degrades to fipronil-sulfide via anaerobic reduction; to fipronil-sulfone via aerobic oxidation; to fipronil-desulfide via photolysis; and to fipronil-amide via hydrolysis. They are too or more toxic than the fipronil and cause serious environmental consequences.

An analytical method for the fipronil determination is needed in order to have a true measure in different matrices 
such as food, soils, water. Chromatographic techniques are the most commonly used tools to determine pesticide residues..$^{711}$ In recent years pre-concentration methods and sample cleanup steps such as quick, easy, cheap, effective, rugged and safe (QuEChERS), ${ }^{12}$ microwave assisted extraction, ${ }^{13}$ extraction with an ionic liquid, ${ }^{14}$ solid phase extraction, ${ }^{15}$ solid phase microextraction ${ }^{16}$ and matrix solid phase dispersion ${ }^{17}$ were employed with good results.

No electroanalytical procedure was found in literature for the fipronil determination. Electroanalytical methods are powerful and versatile tools used to determine species such as antioxidant, drugs, hormones, metals, pesticides and vitamins. ${ }^{18}$ They are fastness, precise, sensitivity, selectivity and low-cost instrumentation. Some pesticides contain electroactive functional groups and voltammetric techniques can be applied for determinations. The graphite-polyurethane (GPU) composite electrode developed by Mendes et al.$^{19}$ combines a high mechanical resistance and an excellent signal/noise ratio which is an excellent sensor for analytical purposes. It exhibited a good performance in electroanalysis of different compounds such as rutin, ${ }^{20}$ imipramine ${ }^{21}$ and heavy metals. ${ }^{22}$

So the purpose of this paper is the electrochemical and quantum chemical investigation of the fipronil insecticide and the development of an analytical methodology for the fipronil determination by square wave stripping voltammetry using the GPU composite electrode. Natural water samples were analyzed to evaluate the proposed method. The theoretical chemical calculations were employed on the fipronil at two different states in the gas and aqueous phases aiming to establish the most probable oxidation sites of the molecule.

\section{Experimental}

A potenciostat/galvanostat Autolab (Ecochemie) model 12/30 PGSTAT interfaced with a computer by the GPES 4.9 software was used for voltammetric measurements. A conventional three electrode cell was used for the voltammetric experiments. The working electrode was a $0.13 \times 1.0 \mathrm{~cm}^{2}$ GPU electrode prepared following the procedure of Mendes et al. ${ }^{19}$ The measured potentials refer to an $\mathrm{Ag} / \mathrm{AgCl}(\mathrm{s})$ electrode in $3.0 \mathrm{~mol} \mathrm{~L}^{-1} \mathrm{KCl}$ aqueous solution. A platinum wire was used as auxiliary electrode. A $1.0 \times 10^{-3} \mathrm{~mol} \mathrm{~L}^{-1}$ stock solution of the fipronil insecticide (Sigma-Aldrich, 97\%) was prepared in ethanol. A $0.1 \mathrm{~mol} \mathrm{~L}^{-1}$ Britton-Robinson (BR) buffer solution was utilized as supporting electrolyte. A $1.0 \mathrm{~mol} \mathrm{~L}^{-1} \mathrm{NaOH}$ solution was used to adjust the $\mathrm{pH}$ values. Cyclic voltammetry measurements were performed to investigate the electrochemical behavior of the fipronil. The scan rate effect was availed in the range from 10 to $300 \mathrm{mV} \mathrm{s}^{-1}$, and the potential range availed was selected from 0.7 to $1.2 \mathrm{~V}$. Square wave voltammetry (SWV) investigations were done with the optimized parameters for the fipronil: frequency $100 \mathrm{~s}^{-1}$, amplitude $50 \mathrm{mV}$ and scan increment $2 \mathrm{mV}$. The parameters of square wave stripping voltammetry (SWSV) such as accumulation potential and time were availed to get the best signal for analytical applications. The accumulation potential was applied to the working electrode for a selected time while the mass transport was controlled at $400 \mathrm{rpm}$. After the accumulation step the electrode was kept in quiescent solution for $15 \mathrm{~s}$ and the voltammograms were recorded by SWV. The SWSV calibration curve was built from 0.5 to $2.5 \times 10^{-6} \mathrm{~mol} \mathrm{~L}^{-1}$. The limits of detection (LOD) and quantification (LOQ) were calculated using the equations below:

$\mathrm{LOD}=\frac{3 \times \mathrm{s}_{\mathrm{B}}}{\mathrm{b}}$

$\mathrm{LOQ}=\frac{10 \times \mathrm{s}_{\mathrm{B}}}{\mathrm{b}}$

where $\mathrm{s}_{\mathrm{B}}$ is the mean of ten blank measurements and $\mathrm{b}$ is the slope of calibration curve.

Recovery studies were carried out in three samples of natural waters using the electroanalytical procedure. $25 \mathrm{~mL}$ of each sample were buffered with BR solution $\mathrm{pH} 8.0$ and fortified with a fipronil ethanolic solution for concentration $(\mathrm{C})$.

Aiming to shed some light into the electro-oxidation process of the fipronil molecule, quantum chemical calculations were performed to evaluate the atomic charge shifts of the system. First, using internal criteria of convergence, a fully unconstrained geometry optimization of the fipronil molecule on the ground state was obtained with Kohn-Sham version of the density-functional theory ${ }^{23,24}$ (KS-DFT) by means of the spin unrestricted B3LYP functional ${ }^{25}$ (Becke three parameter hybrid functional for exchange ${ }^{26}$ with Lee-Yang-Parr functional for electronic correlation $)^{27}$ and $6-31 \mathrm{G}+(\mathrm{d}, \mathrm{p})$ basis $\operatorname{set}^{28}$ for both gas and solvent phases. The geometry optimization processes were followed by a vibrational frequency analysis to confirm that the found structures were in a true minimum of the potential energy surface. The effect of water as implicit solvent was included according to the integral equation formalism of the polarized continuum model (IEFPCM ${ }^{29}$ employing the self-consistent reaction field (SCRF) method. The optimized geometries were then used to calculate the electronic charges over each atom of the system in two different situations, with the fipronil molecule in the ground 
and ionized states (cationic molecule). In both cases, the atomic charges were calculated using the $\mathrm{CHelpG}$ scheme. ${ }^{30}$ In this scheme, the charges are produced to better fit the molecular electrostatic potential of the system at a number of points around the molecule. The charges derived from the electrostatic potential present some advantages since they are, in general, more satisfactory than those calculated with Mulliken population analysis. ${ }^{31}$ For the molecule in the ground and cationic states a spin multiplicity, $\mathrm{M}$, of 1 and 2 was adopted, respectively, according to the expression to distinguish degenerate wavefunctions that differ only in the orientation of their angular spin momenta, $\mathrm{M}=2 \mathrm{~S}+1$, where $S$ is the total sum of the spin vector of the unpaired electrons. Aiming to analyze the atomic charge shifts for the adiabatic ionization process besides the vertical one, a fully unconstrained geometry optimization of the fipronil in the cationic state was also performed in both gas and solvent phases. All calculations were performed with the Gaussian 03 suit of programs. ${ }^{32}$

\section{Results and Discussion}

\section{Cyclic voltammetry}

Figure 2 presents a cyclic voltammogram of a fipronil solution over a GPU electrode.

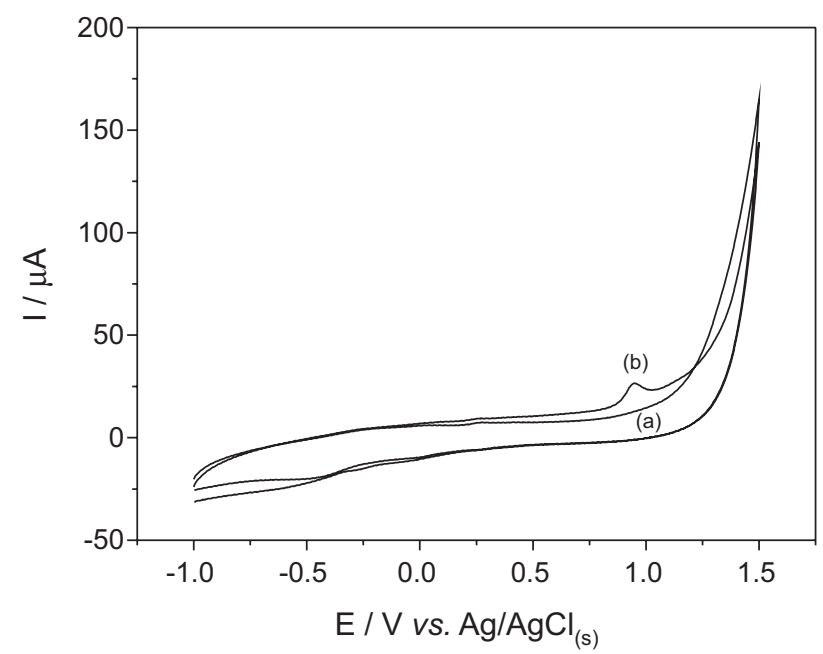

Figure 2. Cyclic voltammograms of (a) $0.1 \mathrm{~mol} \mathrm{~L}^{-1} \mathrm{BR}$ solution, $\mathrm{pH} 8.0$; (b) $5.0 \times 10^{-5} \mathrm{~mol} \mathrm{~L}^{-1}$ fipronil solution; scan rate: $50 \mathrm{mV} \mathrm{s}^{-1}$.

The cyclic voltammogram of the fipronil exhibited a well-defined peak of oxidation in a potential value close to $0.95 \mathrm{~V}$. The absence of a reduction peak asserts the irreversibility of the electrochemical process. The processes at potentials between -0.5 and $0.0 \mathrm{~V}$ refer to polyurethane resin groups. The fipronil presents a hydrophobic character $(\log \mathrm{P}=3.62)$ which favors its adsorption on the surface of the GPU electrode and thus eases the electrochemical oxidation. ${ }^{33}$ Adsorption studies of the fipronil in soil particles demonstrated that the compound has a good affinity for materials with high content of organic matter., ${ }^{2,3}$

\section{Effect of $\mathrm{pH}$}

To evaluate the number of protons involved in the voltammetric fipronil oxidation linear sweep voltammograms were registered in the $\mathrm{pH}$ range of 5.0 to 10.0 in a $5.0 \times 10^{-5} \mathrm{~mol} \mathrm{~L}^{-1}$ of fipronil solution. The results are presented in Figure 3.

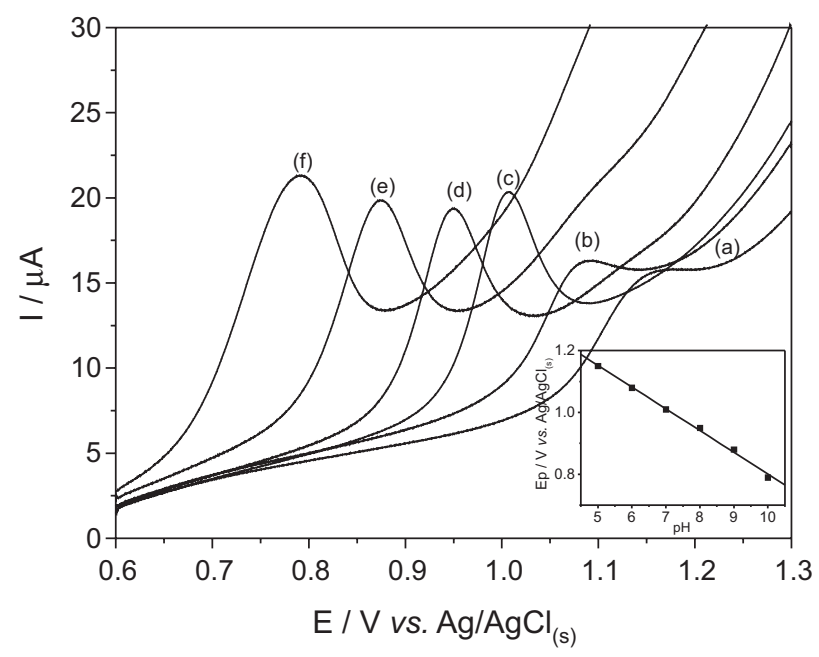

Figure 3. Linear sweeping voltammograms of a $5.0 \times 10^{-5} \mathrm{~mol} \mathrm{~L}^{-1}$ fipronil solution in a $0.1 \mathrm{~mol} \mathrm{~L}^{-1} \mathrm{BR}$ on GPU electrode in different $\mathrm{pH}$ values: (a) 5.0; (b) 6.0; (c) 7.0; (d) 8.0; (e) 9.0; (f) 10.0. Insert Ep versus $\mathrm{pH}$.

Figure 3 shows that the peak potentials shifted linearly to less positive values with increasing $\mathrm{pH}$. A slope of $70.0 \mathrm{mV}$ per $\mathrm{pH}$ was obtained suggesting that the participation of one electron and one proton per molecule of oxidized fipronil. In order to get a low peak potential and a not too high $\mathrm{pH}$ combined with a high intensity and sensitive peak current, the $\mathrm{pH}$ value 8.0 was chosen for a development of an electroanalytical method for the fipronil determination.

\section{Effect of scan rate}

The scan rate was investigated in a solution of fipronil $5.0 \times 10^{-5} \mathrm{~mol} \mathrm{~L}^{-1}$ in the range of 10 to $300 \mathrm{mV} \mathrm{s}^{-1}$. The voltammograms are presented in Figure 4.

The inset plot shows that the relationship Ip $v s$. scan rate is linear with regression coefficient, $r=0.999$, and suggests that the reaction is partially controlled by adsorption of species on the electrode surface. This fact indicates that stripping methods can be applied to detect the substance 


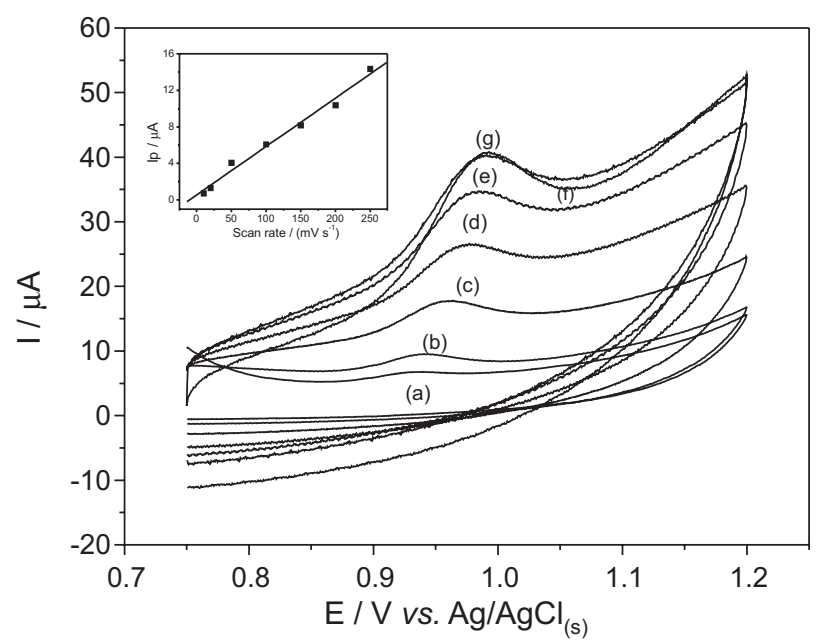

Figure 4. Cyclic voltammograms of a $5.0 \times 10^{-5} \mathrm{~mol} \mathrm{~L}^{-1}$ fipronil solution in a $0.1 \mathrm{~mol} \mathrm{~L}^{-1} \mathrm{BR} \mathrm{pH} 8.0$ in different scan rates: (a) 10; (b) 20; (c) 50; (d) 100; (e) 150; (f) 200; (g) $250 \mathrm{mV} \mathrm{s}^{-1}$. Insert Ip versus scan rate plot.

with better sensitivity and lower limits of detection and quantification.

Figure 5 shows the study of the effect of accumulation potential and time for the fipronil determination by SWSV.

Figure 5A presents the effect of accumulation potential at $120 \mathrm{~s}$. The highest signal peak was seen in the potential value of $0.50 \mathrm{~V}$. So this value was selected for studies of accumulation time. Figure 5B shows that increasing current response is observed from 0 to $120 \mathrm{~s}$. Thus the preconcentration of $120 \mathrm{~s}$ was used to subsequent studies to develop an electroanalytical method for the fipronil determination.

Figure 6 shows square wave stripping voltammograms for the fipronil solutions.

The currents increased linearly with the fipronil concentration over the range $0.50-2.50 \times 10^{-6} \mathrm{~mol} \mathrm{~L}^{-1}$. The parameters of regression linear, LOD and LOQ and recovery percentages of the three natural water samples are presented in Table 1.

The developed method based in SWSV using the GPU composite electrode is simple, fast, reproducible and adequate for routine analysis.

To complement the voltammetric investigations and help to determine the most probable oxidation sites of fipronil molecule, the electronic charge distribution over each atom of the system at the ground and cationic states was determined for both gas and aqueous phases presented in Table 2. The atoms in the first column of the Table 2 are numbered as presented in the Figure 7.

The atomic charges for the ground state were obtained after fully unconstrained geometry optimization in gas and in aqueous phases (second and third columns). The next four columns of the Table 2 show the atomic charges for
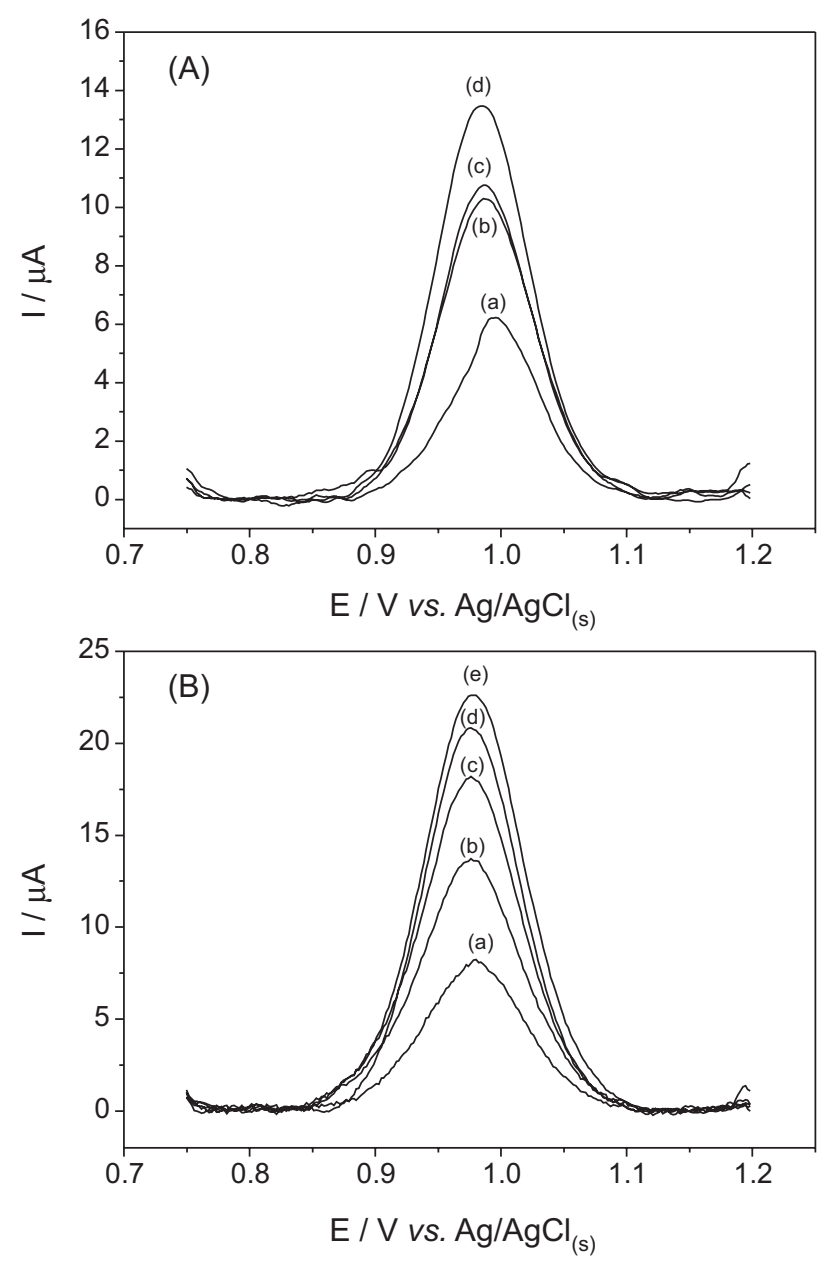

Figure 5. Square wave voltammograms of a $1.0 \times 10^{-6} \mathrm{~mol} \mathrm{~L}^{-1}$ fipronil solution in a $0.1 \mathrm{~mol} \mathrm{~L}^{-1} \mathrm{BR}$ solution, $\mathrm{pH} 8.0 ; \mathrm{f}=100 \mathrm{~s}^{-1}, \mathrm{a}=50 \mathrm{mV}$, $\Delta$ Es $=2 \mathrm{mV}$. (A) Effect of accumulation potential: (a) -1.0 ; (b) 0.0 ; (c) open circuit; (d) $0.5 \mathrm{~V}$. (B) Effect of accumulation time: (a) 0; (b) 30; (c) 60; (d) 90; (e) $120 \mathrm{~s}$

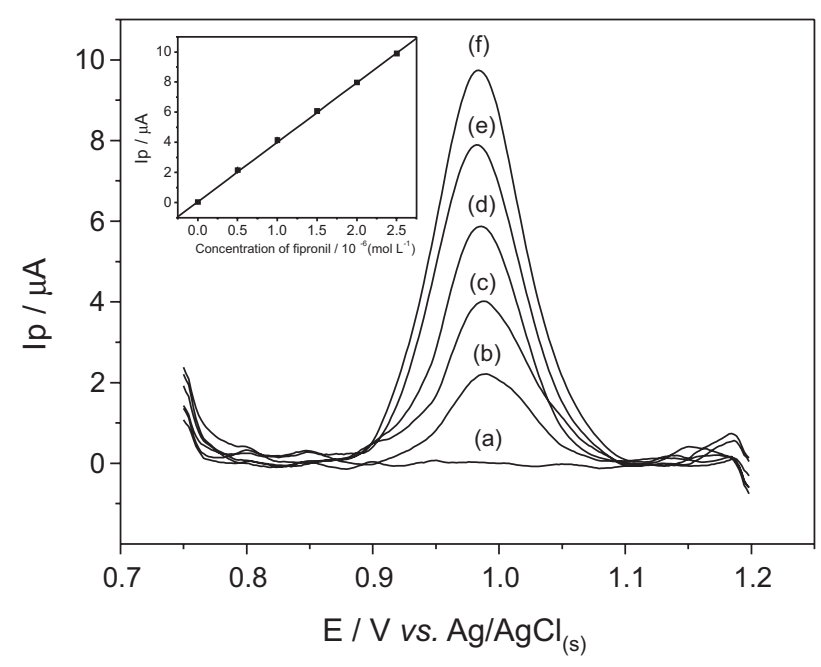

Figure 6. Square wave voltammograms of fipronil solutions in a $0.1 \mathrm{~mol} \mathrm{~L}^{-1} \mathrm{BR}$ solution $\mathrm{pH} 8.0 ; \mathrm{f}=100 \mathrm{~s}^{-1}, \mathrm{a}=50 \mathrm{mV}, \Delta \mathrm{Es}=2 \mathrm{mV}$; Range concentration: (a) 0 ; (b) 0.5 ; (c) 1.0 ; (d) 1.5 ; (e) 2.0 ; (f) $2.5 \times 10^{-6} \mathrm{~mol} \mathrm{~L}^{-1}$. Insert calibration curve. 
Table 1. Parameters of the SWSV calibration plot for fipronil, LOD, LOQ and recovery values on a GPU composite electrode.

\begin{tabular}{|c|c|}
\hline Parameter & Value \\
\hline $\mathrm{b}^{\mathrm{a}} /\left(\mathrm{A} \mathrm{L} \mathrm{mol} \mathrm{L} \mathrm{L}^{-1}\right)$ & 3.95 \\
\hline Relative standard deviation / \% & 0.01 \\
\hline Regression coefficient & 0.999 \\
\hline $\mathrm{s}_{\mathrm{B}}^{\mathrm{b}} / \mu \mathrm{A}$ & $2.41 \times 10^{-3}$ \\
\hline Limit of detection / $\left(\mu \mathrm{g} \mathrm{L} \mathrm{L}^{-1}\right)$ & 0.80 \\
\hline Limit of quantification / $\left(\mu \mathrm{g} \mathrm{L} \mathrm{L}^{-1}\right)$ & 2.67 \\
\hline Recovery sample $1 / \%$ & $101.37 \pm 1.05$ \\
\hline Recovery sample $2 / \%$ & $99.67 \pm 2.32$ \\
\hline Recovery sample $3 / \%$ & $100.33 \pm 1.18$ \\
\hline
\end{tabular}

${ }^{\mathrm{a} b}$ : slope of calibration curve; ${ }^{\mathrm{b}}{ }_{\mathrm{B}}$ : mean of ten blank measurements. the oxidized state also in gas and in aqueous phases. For each phase, two different situations were considered; the vertical ionization (fourth and sixth columns) with charges obtained from the same geometry as those of the ground state, and the adiabatic ionization (fifth and seventh columns) with charges obtained after fully unconstrained geometry optimization at the cationic state. That allows four different analysis of the atomic charge variation of the fipronil (the last four columns of the Table 2), for vertical and adiabatic ionizations in the gas phase and in the aqueous phases.

From the last four columns of the Table 2, it can be noted that the overall tendency of the atomic charge variation remains the same independently of the phase and of the ionization process considered. The vertical

Table 2. Atomic charges for the fipronil molecule in ground state and after oxidation obtained with CHelpG scheme

\begin{tabular}{|c|c|c|c|c|c|c|c|c|c|c|}
\hline \multirow{3}{*}{ Atom } & \multicolumn{2}{|c|}{ Ground state / a.u. } & \multicolumn{4}{|c|}{ Cationic state / a.u. } & \multirow{3}{*}{$\begin{array}{c}\Delta(\text { gas } \\
\text { vertical }) / \text { a.u. }\end{array}$} & \multirow{3}{*}{$\begin{array}{c}\Delta(\text { gas } \\
\text { adiabatic) / a.u. }\end{array}$} & \multirow{3}{*}{$\begin{array}{c}\Delta(\text { water, } \\
\text { vertical) / a.u. }\end{array}$} & \multirow{3}{*}{$\begin{array}{c}\Delta(\text { water, } \\
\text { adiabatic) / a.u. }\end{array}$} \\
\hline & \multirow{2}{*}{ Gas } & \multirow{2}{*}{ Water } & \multicolumn{2}{|c|}{ Gas } & \multicolumn{2}{|c|}{ Water } & & & & \\
\hline & & & Vertical & Adiabatic & Vertical & Adiabatic & & & & \\
\hline $\mathrm{C} 1$ & -0.02 & -0.07 & 0.00 & -0.04 & -0.03 & -0.01 & 0.02 & -0.02 & 0.04 & 0.06 \\
\hline $\mathrm{C} 2$ & -0.06 & -0.01 & -0.06 & -0.04 & -0.02 & -0.03 & 0.00 & 0.02 & -0.01 & -0.02 \\
\hline $\mathrm{C} 3$ & 0.37 & 0.31 & 0.31 & 0.24 & 0.26 & 0.25 & -0.06 & -0.12 & -0.05 & -0.05 \\
\hline $\mathrm{C} 4$ & -0.09 & -0.03 & -0.08 & -0.04 & -0.04 & -0.04 & 0.00 & 0.05 & -0.01 & -0.02 \\
\hline $\mathrm{C} 5$ & -0.02 & -0.05 & 0.01 & -0.03 & -0.03 & 0.00 & 0.02 & -0.01 & 0.02 & 0.05 \\
\hline C6 & -0.14 & -0.09 & -0.12 & -0.08 & -0.08 & -0.10 & 0.03 & 0.07 & 0.01 & -0.01 \\
\hline $\mathrm{H} 7$ & 0.12 & 0.16 & 0.14 & 0.15 & 0.16 & 0.14 & 0.02 & 0.03 & 0.00 & -0.02 \\
\hline H8 & 0.12 & 0.15 & 0.13 & 0.14 & 0.15 & 0.13 & 0.02 & 0.02 & 0.00 & -0.01 \\
\hline $\mathrm{Cl} 9$ & -0.02 & -0.05 & 0.03 & 0.01 & 0.00 & -0.01 & 0.05 & 0.03 & 0.04 & 0.04 \\
\hline Cl10 & -0.05 & -0.07 & -0.01 & 0.00 & -0.04 & -0.03 & 0.04 & 0.05 & 0.03 & 0.04 \\
\hline N11 & 0.13 & 0.16 & 0.03 & 0.12 & 0.09 & 0.17 & -0.10 & -0.01 & -0.06 & 0.02 \\
\hline $\mathrm{C} 12$ & 0.24 & 0.29 & 0.25 & 0.28 & 0.25 & 0.32 & 0.01 & 0.04 & -0.04 & 0.03 \\
\hline C13 & -0.07 & -0.12 & -0.06 & -0.09 & -0.04 & -0.05 & 0.01 & -0.02 & 0.08 & 0.06 \\
\hline C14 & 0.20 & 0.21 & 0.27 & 0.32 & 0.29 & 0.30 & 0.07 & 0.12 & 0.09 & 0.10 \\
\hline N15 & -0.50 & -0.58 & -0.28 & -0.32 & -0.33 & -0.38 & 0.22 & 0.18 & 0.25 & 0.20 \\
\hline N16 & -0.71 & -0.77 & -0.48 & -0.58 & -0.38 & -0.49 & 0.23 & 0.13 & 0.39 & 0.27 \\
\hline $\mathrm{H} 17$ & 0.29 & 0.38 & 0.29 & 0.33 & 0.36 & 0.38 & 0.00 & 0.04 & -0.02 & 0.01 \\
\hline H18 & 0.35 & 0.41 & 0.36 & 0.43 & 0.38 & 0.43 & 0.01 & 0.07 & -0.03 & 0.02 \\
\hline S19 & 0.28 & 0.43 & 0.42 & 0.33 & 0.54 & 0.45 & 0.14 & 0.05 & 0.11 & 0.02 \\
\hline $\mathrm{O} 20$ & -0.41 & -0.56 & -0.30 & -0.31 & -0.46 & -0.45 & 0.11 & 0.11 & 0.10 & 0.11 \\
\hline $\mathrm{C} 21$ & 0.42 & 0.41 & 0.34 & 0.47 & 0.30 & 0.44 & -0.08 & 0.04 & -0.11 & 0.02 \\
\hline $\mathrm{C} 22$ & 0.73 & 0.73 & 0.68 & 0.67 & 0.70 & 0.68 & -0.05 & -0.06 & -0.03 & -0.05 \\
\hline F23 & -0.23 & -0.26 & -0.20 & -0.19 & -0.24 & -0.23 & 0.03 & 0.04 & 0.02 & 0.02 \\
\hline $\mathrm{F} 24$ & -0.23 & -0.24 & -0.20 & -0.20 & -0.22 & -0.22 & 0.03 & 0.03 & 0.01 & 0.02 \\
\hline F25 & -0.24 & -0.24 & -0.22 & -0.22 & -0.23 & -0.23 & 0.02 & 0.02 & 0.01 & 0.02 \\
\hline F26 & -0.20 & -0.17 & -0.15 & -0.18 & -0.13 & -0.14 & 0.05 & 0.02 & 0.04 & 0.03 \\
\hline F27 & -0.13 & -0.15 & -0.08 & -0.13 & -0.11 & -0.15 & 0.05 & 0.00 & 0.04 & 0.01 \\
\hline F28 & -0.11 & -0.13 & -0.04 & -0.07 & -0.06 & -0.10 & 0.07 & 0.05 & 0.06 & 0.02 \\
\hline $\mathrm{C} 29$ & 0.43 & 0.51 & 0.32 & 0.31 & 0.41 & 0.41 & -0.11 & -0.12 & -0.10 & -0.10 \\
\hline N30 & -0.45 & -0.56 & -0.30 & -0.30 & -0.45 & -0.44 & 0.14 & 0.15 & 0.11 & 0.12 \\
\hline
\end{tabular}




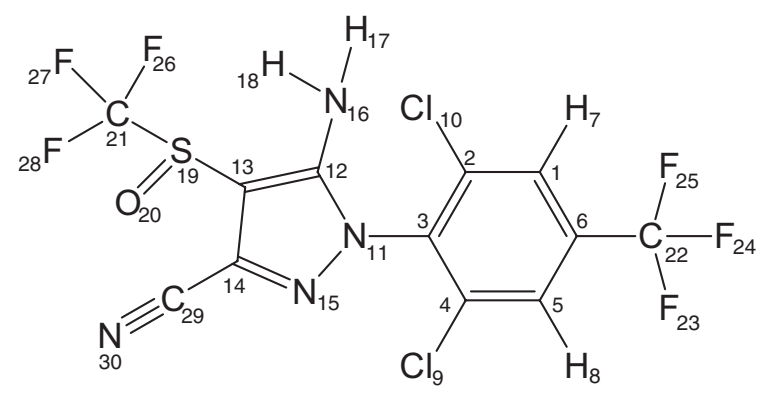

Figure 7. Numbered fipronil's structure.

ionization in the gas phase, $\Delta$ (gas, vertical), shows that the highest variation in the atomic charges of the system after the removal of an electron relies on the nitrogen, $\mathrm{N} 15$ and N16, of the pyrazole ring indicating this as the most probable oxidation site of the fipronil molecule. The second most probable oxidation sites of fipronil molecule relies on the sulfur atom of the sulfoxide group, $\mathrm{S} 19$, on the nitrogen atom of cyanide group, N30, and on the oxygen of sulfoxide group, O20. For the adiabatic ionization process in the gas phase, $\Delta$ (gas, adiabatic), both nitrogens N15 and N16 remain as important oxidation sites although less pronounced than for the vertical ionization. This is an expected effect, since the geometry optimization of the cationic state causes a charge delocalization which reduces the strength of the N15, N16, and S19 as oxidation site and increases the importance of $\mathrm{C} 14$, the carbon atom of the pyrazole ring to which the cyanide group is attached. On the other hand, the inclusion of the solvent effect in the vertical ionization process, $\Delta$ (water, vertical), stress the charge localization observed in the gas phase increasing the strength mainly of the N16 over the N15 as an oxidation site. Finally, the inclusion of the solvent effect in adiabatic ionization process, $\Delta$ (water, adiabatic), although causing a charge delocalization, does not take the place of both N16 and N15 away from the most probable oxidation sites of the fipronil molecule, followed by the nitrogen of the cyanide group, N30, the oxygen of the sulfoxide group, O20, and carbon of the pyrazole ring to which the cyanide group is attached. It is worth to note that electrochemical oxidation of organic compounds containing nitrogen consists in the removing of an electron from the nitrogen atom forming a cation. Nuclear magnetic resonance and mass spectrometry studies are necessary to complement this work to purpose an electrochemical mechanism of the fipronil oxidation.

In a very recent work, Taillebois et al. ${ }^{34}$ performed a conformational study and molecular electrostatic potential calculation of the fipronil molecule among other pesticides. After full geometry optimizations using
M06-2X density-functional and 6-311G(d) basis set function, their conformation study in the gas phase revealed eleven energetic minima for the fipronil. These energetic minima were found considering the rotation of two dihedral angles, one involving the dichlorobenzotrifluoride and the amino-cyanopyrazole rings (named D1 by the authors), and another concerning the amino-cyanopyrazole ring and the trifluoromethylsulfinyl group (named D2 by the authors). The two most stable gas phase conformations show a dihedral angle D1 of -77 and $-103^{\circ}$ while in our fully optimized gas phase structure the same dihedral angle is $-86.1^{\circ}$. This difference in the dihedral angle between the two rings of the fipronil, probably related to the density-functional and the basis set functions adopted, although causing a large influence on the atomic charge of the chlorine atoms, should not impact the atomic charges of the nitrogens, N16, N15, and N30, sulfur, S19, and oxygen, O20, on the same way, as demonstrated by the molecular electrostatic calculations performed by Taillebois et al..$^{34}$ The same discussion can be made for the other dihedral angle of fipronil involving the amino-cyanopyrazole ring and the trifluoromethylsulfinyl group studied by Taillebois et al. ${ }^{34}$ since again, their calculated molecular electrostatic potential for the nitrogens, oxygen and sulfur atoms, the most evident oxidizing sites according to our investigation for vertical and adiabatic processes in gas and aqueous phases, do not show significant changings.

Also in a recent work, Jiang et al. ${ }^{35}$ evaluated an experimental and theoretical study on the (3-cyano-1-(2,6dichloro-4-(trifluoromethyl)phenyl)-4-((trifluoromethyl) sulfinyl)-1H-pyrazol-5-yl)(2-(triethylammonio)acetyl) amide, a very close related system to fipronil. The molecular geometry obtained from their optimization with B3LYP density-functional, LANL2DZ basis set for chlorine and sulfur, and 6-31++G(d,p) basis set for the other atoms show few bond distances slightly longer than that obtained from their X-ray diffraction. The theoretical dihedral angle involving the dichlorobenzotrifluoride and the amino-cyanopyrazole rings is very similar to that found in the X-ray diffraction experiment, -93.1 and $-92.7^{\circ}$, respectively, and agrees better with that found in this work, $-86.1^{\circ}$, than that found by Taillebois et al.,$^{34}-77$ and $-103^{\circ}$. Again, the role played by the density-functional and basis set functions seems to be important. The other dihedral angle involving the amino-cyanopyrazole ring and the trifluoromethylsulfinyl group, equals to -107.1 and $-111.5^{\circ}$ for the theoretical and experimental study, respectively, of Jiang et al. ${ }^{35}$ differs from that obtained by us for the ground state fipronil in the gas phase, equals to $-79.4^{\circ}$, being, however, very close of that for the cationic state in the gas phase, equals to $-111.2^{\circ}$. 


\section{Conclusions}

Fipronil exhibits an irreversible behavior with a well defined peak at $0.95 \mathrm{~V}$ over the GPU electrode. The mass transport is controlled partially by diffusion and adsorption of species on the electrode surface. The method based in square wave stripping voltammetry was fast, low cost and sensitive for the fipronil determination. The limits of detection and quantification were 0.80 and $2.67 \mu \mathrm{g} \mathrm{L} \mathrm{L}^{-1}$, respectively. The recovery values of three natural water samples were near $100 \%$. Quantum chemical calculations based on KS-DFT using B3LYP/6-31G+(d,p) approach and CHelpG scheme indicate that the most probable oxidation site of the fipronil molecule relies on the nitrogen atoms of the pyrazole ring since both atoms presented the highest atomic charge variation after the oxidation process.

\section{Acknowledgments}

The authors acknowledge the Brazilian Agencies CAPES and CNPq for the financial support.

\section{References}

1. Tingle, C. C.; Rother, J. A.; Dewhurst, C. F.; Lauer, S.; King, W. J.; Rev. Environ. Contam. Toxicol. 2003, 176, 1.

2. Bobe, A.; Cooper, J. F.; Colste, C. M.; Muller, M. A.; Pestic. Sci. 1998, 52, 275.

3. Bobe, A.; Colste, C. M.; Cooper, J. F.; J. Agric. Food Chem. 1997, 45, 4861 .

4. http://npic.orst.edu/factsheets/fipronil.pdf accessed in November 2015.

5. Cole, L. M.; Nicholson, R. A.; Casida, J. E.; Pestic. Biochem. Physiol. 1993, 46, 47.

6. Pei, Z.; Yitong, L.; Baofeng, L.; Gan, J. J.; Chemosphere 2004, 57, 1691

7. Jiménez, J. J.; Bernal, J. L.; del Nozal, M. J.; Martín, M. T.; Mayo, R.; J. Chromatogr. A 2008, 1187, 40.

8. Sánchez-Brunete, C.; Miguel, E.; Albero, B.; Tadeo, J. L.; Span. J. Agric. Res. 2008, 6, 7.

9. Bichon, E.; Richard, C. A.; le Bizec, B.; J. Chromatogr. A 2008 , 1201,91

10. Kadar, A.; Faucon, J. P.; J. Agric. Food Chem. 2006, 54, 9741.

11. Hadjmohammadi, M. R.; Nikou, S. M.; Kamel, K.; Acta Chim. Slov. 2006, 53, 517.

12. Brondi, S. H. G.; Macedo, A. N.; Vicente, G. H. L.; Nogueira, A. R. A.; Bull. Environ. Contam. Toxicol. 2011, 22, 18.

13. Coscolla, C.; Castillo, M.; Pastor, A.; Yusa, V.; Anal. Chim. Acta 2011, 693, 72 .

14. Liu, Y.; Zhao, E.; Zhu, W.; Gao, H.; Zhou, Z.; J. Chromatogr. A 2009, 1216, 885.
15. Jiménez, J. J.; Bernal, J. L.; del Nozal, M. J.; Martín, M. T.; Mayo, R.; J. Chromatogr. A 2007, 1146, 8.

16. Vílchez, J. L.; Prieto, A.; Araujo, L.; Navalón, A.; J. Chromatogr. A 2001, 919, 215.

17. Morzycka, B.; J. Chromatogr. A 2002, 982, 267.

18. Wang, J.; Electroanalytical Techniques in Clinical Chemistry and Laboratory Medicine; VCH Publishers: New York, 1988.

19. Mendes, R. K.; Claro-Neto, S.; Cavalheiro, E. T. G.; Talanta 2002, 57, 909.

20. Malagutti, A. R.; Zuin, V. G.; Cavalheiro, E. T. G.; Mazo, L. H.; Electroanalysis 2006, 18, 1028.

21. Toledo, R. A.; Santos, M. C.; Honorio, K. M.; da Silva, A. B. F.; Cavalheiro, E. T. G.; Mazo, L. H.; Anal. Lett. 2006, 39, 507.

22. Cesarino, I.; Cavalheiro, E. T. G.; Brett, C. M. A.; Electroanalysis 2010, 22, 61 .

23. Hohenberg, P.; Kohn, W.; Phys. Rev. 1964, 136, B864.

24. Kohn, W.; Sham, L. J.; Phys. Rev. 1965, 140, A1133.

25. Becke, A. D.; J. Chem. Phys. 1993, 98, 5648.

26. Becke, A. D.; J. Chem. Phys. 1993, 98, 1372.

27. Lee, C.; Yang, W.; Parr, R. G.; Phys. Rev. B: Condens. Matter Mater. Phys. 1988, 37, 785.

28. Petersson, G. A.; Al-Lahan, M. A.; J. Chem. Phys. 1991, 94, 6081.

29. Tomasi, J.; Mennucci, B.; Cammi, R.; Chem. Rev. 2005, 105, 2999.

30. Breneman, C. M.; Wiberg, K. B.; J. Comput. Chem. 1990, 11, 361.

31. Singh, U. C.; Kollman, P. A.; J. Comput. Chem. 1984, 5, 129.

32. Frisch, M. J.; Trucks, G. W.; Schlegel, H. B.; Scuseria, G. E.; Robb, M. A.; Cheeseman, J. R.; Montgomery Jr., J. A.; Vreven, T.; Kudin, K. N.; Burant, J. C.; Millam, J. M.; Iyengar, S. S.; Tomasi, J.; Barone, V.; Mennucci, B.; Cossi, M.; Scalmani, G.; Rega, N.; Petersson, G. A.; Nakatsuji, H.; Hada, M.; Ehara, M.; Toyota, K.; Fukuda, R.; Hasegawa, J.; Ishida, M.; Nakajima, T.; Honda, Y.; Kitao, O.; Nakai, H.; Klene, M.; Li, X.; Knox, J. E.; Hratchian, H. P.; Cross, J. B.; Bakken, V.; Adamo, C.; Jaramillo, J.; Gomperts, R.; Stratmann, R. E.; Yazyev, O.; Austin, A. J.; Cammi, R.; Pomelli, C.; Ochterski, J. W.; Ayala, P. Y.; Morokuma, K.; Voth, G. A.; Salvador, P.; Dannenberg, J. J.; Zakrzewski, V. G.; Dapprich, S.; Daniels, A. D.; Strain, M. C.; Farkas, O.; Malick, D. K.; Rabuck, A. D.; Raghavachari, K.; Foresman, J. B.; Ortiz, J. V.; Cui, Q.; Baboul, A. G.; Clifford, S.; Cioslowski, J.; Stefanov, B. B.; Liu, G.; Liashenko, A.; Piskorz, P.; Komaromi, I.; Martin, R. L.; Fox, D. J.; Keith, T.; Al-Laham, M. A.; Peng, C. Y.; Nanayakkara, A.; Challacombe, M.; Gill, P. M. W.; Johnson, B.; Chen, W.; Wong, M. W.; Gonzalez, C.; Pople, J. A.; Gaussian Version 2004/3; Gaussian Inc., Wallingford, CT, USA, 2004.

33. http://www.fao.org/fileadmin/templates/agphome/documents/ Pests_Pesticides/Specs/fipronil09.pdf accessed in November 2015. 
34. Taillebois, E.; Alamiddine, Z.; Brazier, C.; Graton, J.; Laurent, A. D.; Thany, S. H.; le Questel, J.-Y.; Bioorg. Med. Chem. 2015, 23, 1540.
35. Jiang, D. X.; Zheng, X. H.; Xu, H. H.; Wong, N. B.; Crystallogr. Rep. 2014, 59, 1078.

Submitted: July 31, 2015

Published online: December 7, 2015

FAPESP has sponsored the publication of this article. 